\title{
RAM SEMINAL PLASMA AND FERTILITY: RESULTS FROM AN ONGOING FIELD STUDY
}

\author{
Sophia Belibasaki ${ }^{1 *}$, G. S. Amiridis ${ }^{2}$, A. Lymberopoulos ${ }^{1}$, Sophia VARSAKeli ${ }^{1}$ \\ and Theodora KOUSKOURA ${ }^{1}$ \\ ${ }^{1}$ NAGREF, Veterinary Research Institute, 57008 Ionia, Thessaloniki, Greece; \\ ${ }^{2}$ Department of Obstetrics and Reproduction, Faculty of Veterinary Medicine, \\ University of Thessaly, Karditsa, Greece
}

(Received July 23, 1999; accepted May 3, 2000)

\begin{abstract}
The effects of partial replacement of ram semen diluent with ram seminal plasma on the fertility of ewes were studied. Crossbred Chios ewes $(n=152)$ were assigned to six groups. The oestrous cycles of the ewes were synchronised at the peak (Groups A, B, C and D) and at the end (Groups E and F) of the breeding season by means of intravaginal sponges impregnated with fluorogestone acetate (FGA) for 14 days. Four hundred IU of PMSG were injected intramuscularly at the time of sponge removal. Ewes of Groups A, C and E were artificially inseminated with ram semen diluted with skim milk extender, while those of Groups B, $\mathrm{D}$ and $\mathrm{F}$ with ram semen diluted with $50 \%$ skim milk and $50 \%$ ram seminal plasma. The addition of ram seminal plasma induced a significant increase $(\mathrm{P}<$ $0.05)$ in litter size in Groups B and D when compared with that of Groups A and $\mathrm{C}$ (1.85 and 1.88 vs. 1.39 and 1.52 , respectively). This increase was not significant when insemination was performed at the end of the breeding season $(2.0 \mathrm{vs}$. 1.4). These results indicate that the addition of seminal plasma can influence the fertility of ewes or the fertilising capacity of extended ram semen to some extent.
\end{abstract}

Key words: Artificial insemination, semen, seminal plasma, ram

When artificial insemination (AI) rather than natural mating is used, ewes are not exposed to the normal concentration of seminal plasma (s. p.) because the ejaculate is diluted before use. While every effort is made to ensure that the optimum number of sperm cells is administered through AI, there is no attempt to compensate for the reduced concentrations of other components of the ejaculate.

The role of seminal plasma and its effect on the fertilising capacity of semen has been a matter of debate in the last years. It has been suggested that, apart from its function as a transport medium for spermatozoa, seminal plasma may have additional roles. These functions are based on direct interactions between seminal plasma and spermatozoa, while some other effects are directed at

*E-mail: iats@the.forthnet.gr; Fax: +31 781161 
the female genital tract and thereby can indirectly influence the physiology of spermatozoa.

These functions include nutrition (Mann and Lutwak-Mann, 1981a), capacitation (McRorie and Williams, 1974), increase of uterine contractions (Claus, 1990), advancement of ovulation (Weitze et al., 1990a, 1990b), immunosuppression, providing protection to both sperm and embryos in early life (Koch and Ellendorff, 1985), antimicrobial activity, relaxation of the tubal isthmus (Waberski, 1996), and gamete recognition and binding (Töpfer-Petersen, 1996).

In the ram, an ejaculate amounts to $0.7-2 \mathrm{ml}$ but it has a relatively high sperm density (2-5 million/ $\mu$ l) and, when subjected to high-speed centrifugation, it yields about one-quarter to one-third firmly packed spermatozoa, the remainder being seminal plasma (Mann and Lutwak-Mann, 1981b).

Dilution of ram semen reduces the amount of seminal plasma by two to ten times and might thereby minimise the beneficial effects of seminal fluid on fertilisation, especially the effects based on the interaction of seminal plasma with the female genital tract. So far, emphasis has been given to the biochemical composition of the diluent (fructose, sorbitol, citric acid, etc.). Little knowledge exists on the role of hormone concentration (testosterone, progesterone and oestrogen) in both seminal plasma and extenders.

The objective of this preliminary study was to investigate the effects of the partial replacement of semen diluent with seminal plasma on the fertility of artificially inseminated ewes.

\section{Materials and methods}

\section{Animals}

The study was conducted in three flocks from the same area of Northern Greece. A total of 152 multiparous crossbred Chios milking ewes aged 3 to 5 years were used. Sixty Chios crossbred ewes from Flock 1 were divided into two groups (Group A $=30$ ewes and Group B = 30 ewes) and synchronised at the peak of the breeding season (August). Sixty-five crossbred Chios ewes from Flock 2 were synchronised at the peak of the breeding season (a week later than Flock 1) and the flock was divided into two groups (Group $\mathrm{C}=34$ ewes and Group $\mathrm{D}=31$ ewes). Twenty-seven Chios $\times$ Friesland ewes from Flock 3 were synchronised at the end of the breeding season (end of November) and the flock was divided into two groups (Group $\mathrm{E}=14$ ewes and Group $\mathrm{F}=13$ ewes).

\section{Oestrus synchronisation}

Oestrus synchronisation was carried out by means of intravaginal sponges impregnated with fluorogestone acetate (FGA) for 14 days $\left(\right.$ Chronogest ${ }^{\circledR}$, Inter- 
vet, The Netherlands) and the ewes were treated with 400 IU of PMSG (Intergonan $^{\circledR}$, Intervet, Holland) at the time of sponge removal.

\section{Seminal plasma preparation}

A week before the scheduled AI, ejaculates were collected from six Chios rams. Seminal plasma was obtained by centrifuging the fresh ejaculates at $1400 \times g$ for $10 \mathrm{~min}$. The supernatant clear seminal plasma was stored at $-30{ }^{\circ} \mathrm{C}$ until use.

\section{Semen collection and preparation}

Semen was collected using artificial vagina from the same six Chios rams that had been used as seminal plasma donors, and checked for its traits (viability more than $80 \%$, motility score higher than 4 ). Then the pool of this semen was divided into two parts $\left(\mathrm{A}_{1}\right.$ and $\left.\mathrm{B}_{1}\right)$. Part $\mathrm{A}_{1}$ of the pool was diluted with skim milk extender so that each insemination dose $(0.25 \mathrm{ml})$ contained $200 \times 10^{6}$ motile spermatozoa. Part $\mathrm{B}_{1}$ of the pool was diluted with $50 \%$ skim milk diluent and $50 \%$ ram seminal plasma, and each dose contained the same number of spermatozoa as part $\mathrm{A}_{1}$.

\section{Evaluation of motility}

Motility in both semen parts was determined (1) after collection and (2) at three-hour intervals after dilution and incubation at $37^{\circ} \mathrm{C}$.

The percentage of motile spermatozoa was estimated by visual microscopic observation, following eosin-negrosin staining.

The diluted semen was packed into mini $(0.25 \mathrm{ml})$ French polyvinyl straws and stored at $16{ }^{\circ} \mathrm{C}$ until used for insemination. Ewes of Groups A, C and $\mathrm{E}$ (controls) were inseminated intracervically with semen $\mathrm{A}_{1}$ while ewes of Groups B, D and F (treated) with semen $\mathrm{B}_{1}$. In all groups two artificial inseminations were applied at $48 \mathrm{~h}$ and $72 \mathrm{~h}$ after sponge removal.

\section{Statistics}

Time-dependent differences between semen parts were tested using regression analysis, considering a dummy value $(D=1,2)$ for semen treatment.

Differences in lambing percentage and litter size between control and treated groups were analyzed by $\mathrm{X}^{2}$ and $t$-test, respectively, significance being taken at the level of $\mathrm{P}<0.05$. 


\section{Results}

Results on semen motility are presented in Table 1.

\section{Table 1}

Motility (\%) of the pooled semen (MAC) and the two parts $\left(\mathrm{A}_{1}\right.$ and $\left.\mathrm{B}_{1}\right)$ at one-hour intervals after supplementation of the extenders

\begin{tabular}{|c|c|c|c|c|c|c|c|}
\hline & \multirow{2}{*}{ MAC } & \multicolumn{2}{|c|}{ M1 } & \multicolumn{2}{|c|}{ M2 } & \multicolumn{2}{|c|}{ M3 } \\
\hline & & $\mathrm{A}_{1}$ & $\mathrm{~B}_{1}$ & $\mathrm{~A}_{1}$ & $\mathrm{~B}_{1}$ & $\mathrm{~A}_{1}$ & $\mathrm{~B}_{1}$ \\
\hline Trial 1 & 86 & 59 & 66 & 46 & 50 & 24 & 51 \\
\hline Trial 2 & 81 & 60 & 62 & 45 & 53 & 25 & 50 \\
\hline Trial 3 & 85 & 63 & 65 & 47 & 50 & 28 & 52 \\
\hline
\end{tabular}

$\%$ motility $=69.03( \pm 6.55)+11.33( \pm 2.70) \times$ Treatment $^{*}-12.08( \pm 1.66) \times \mathrm{t}^{* *}$ $\mathrm{F}=35.44552$; sign $\mathrm{F}<0.00005$

${ }^{*}$ Treatment: dummy variable, 1 : skim milk diluent, $2:+50 \%$ ram seminal plasma

${ }^{* *} \mathrm{t}=$ time (in hours) after semen collection

Twenty-three out of 30 ewes (76.6\%) gave birth to 32 lambs in Group A and 26 out of 30 ewes $(86.6 \%)$ gave birth to 48 lambs in Group B. The litter size was 1.39 and $1.85(\mathrm{P}<0.05)$, respectively (Table 2$)$.

Seventeen out of 34 ewes (50.0\%) gave birth to 26 lambs in Group C and 18 out of 31 ewes $(58.06 \%)$ gave birth to 34 lambs in Group D. The litter size was 1.52 and $1.88(\mathrm{P}<0.01)$, respectively (Table 2$)$.

Five ewes (35.7\%) gave birth to 7 lambs in Group E and 5 ewes (38.46\%) gave birth to 10 lambs in Group F. The litter size was 1.4 and 2.0, respectively (Table 2).

Table 2

Lambing results and litter size of artificially inseminated ewes in Flocks 1, 2 and 3

\begin{tabular}{lccccc}
\hline Group & $\begin{array}{c}\text { No. } \\
\text { of ewes }\end{array}$ & $\begin{array}{c}\text { No. of lambing } \\
\text { ewes }\end{array}$ & $\begin{array}{c}\text { Percentage of } \\
\text { lambing ewes (\%) }\end{array}$ & Lambs born & Mean litter size \\
\hline $\mathrm{A}^{*}$ & 30 & 23 & 76.6 & 32 & $1.39 \pm 0.58^{\mathrm{a}}$ \\
$\mathrm{B}^{* *}$ & 30 & 26 & 86.6 & 48 & $1.85 \pm 0.53^{\mathrm{b}}$ \\
$\mathrm{C}^{*}$ & 34 & 17 & 50.0 & 26 & $1.52 \pm 0.51^{\mathrm{a}}$ \\
$\mathrm{D}^{* *}$ & 31 & 18 & 58.06 & 34 & $1.88 \pm 0.58^{\mathrm{b}}$ \\
$\mathrm{E}^{*}$ & 14 & 5 & 35.7 & 7 & $1.40 \pm 0.54^{\mathrm{a}}$ \\
$\mathrm{F}^{* *}$ & 13 & 5 & 38.46 & 10 & $2.00 \pm 0.70^{\mathrm{a}}$ \\
\hline
\end{tabular}

${ }^{*}$ Control $=$ skim milk semen diluent; ${ }^{* *}$ Treated $=$ partial replacement of the diluent with ram seminal plasma. Data within columns with different superscripts differ significantly $(\mathrm{P}<0.05)$ 


\section{Discussion}

Supplementation of the extender with seminal plasma increased the percentage of motile spermatozoa after the second hour of incubation. These results are in agreement with those of Ashworth et al. (1994), who reported that supplementation of seminal plasma in the diluent extends the survival of spermatozoa under in vitro conditions. Furthermore, seminal plasma has been found to increase the percentage of motile spermatozoa during cooling, freezing and thawing (Graham, 1994).

An increase in the percentage of lambing ewes was observed in all groups in which semen diluent was partly replaced by seminal plasma, but this increase was not statistically significant. As expected, more ewes conceived when inseminated at the peak rather than at the end of the breeding season $(86.6 \%$ and $58.06 \%$ vs. $38.48 \%$ and $76.6 \%$ and $50.0 \%$ vs. $35.7 \%$ for treated and control groups, respectively). This is in agreement with the findings of Edey et al. (1978) and Williams et al. (1978), who suggest that fertility may vary according to the stage of the breeding season. A difference was observed in the percentage of lambing ewes between the two flocks synchronised at the peak of the breeding season, possibly due to different management conditions.

A significant increase was found in litter size of the treated groups in the flocks that were synchronised at the peak of the breeding season. It appears that partial replacement of the semen extender with ram seminal plasma can have a beneficial effect on ovulation, fertilisation, in providing protection to semen and early embryos, or it can exert a combined positive effect on all the abovementioned factors. Although an increase in litter size (2.0 vs. 1.4) was observed also in the treated group of the third flock, this difference was not significant, probably due to the small number of ewes that conceived.

In sheep, approximately 25 to $40 \%$ of fertilised eggs are lost during the first three weeks of pregnancy, resulting in reduced conception rate and litter size (Bolet, 1986), with the majority of these embryos being capable of normal development (Wilmut et al., 1986). It is well established that embryonic loss is attributable to hormonal deficiencies and/or imbalance. It is also well known that seminal plasma contains powerful immunosuppressive agents that prevent the hypersensitisation of females to the alloantigenic proteins on the surface of spermatozoa and to the seminal plasma (Fahmi et al., 1985; Fahmi and Hunter, 1986). On the other hand, these agents protect the spermatozoa from destruction by cells and molecules of the female immune system (James and Hargreave, 1984).

Ollero et al. (1997) have reported that in washed frozen ram semen the presence of whole re-added seminal plasma maintained a higher rate of sperm heterogeneity and viability. Moreover, in a recent study Garner et al. (1999) reported that addition of seminal plasma to frozen bull semen increased sperm viability. 
It has also been reported that in pigs seminal plasma may regulate female reproductive functions by advancing the time of ovulation (Weitze et al., 1990b). Supposing that the case is similar in sheep, this would explain the higher conception rate found after insemination with seminal plasma supplemented semen, since the presence of seminal plasma in the first insemination could possibly advance the time of ovulation or increase the number of ovulated follicles. Moreover, seminal plasma could contribute to the extension of semen longevity and this could make possible the fertilisation of oocytes from late ovulations.

The results presented here indicate that addition of seminal plasma to the semen extender can increase the litter size in ewes, at least when it is used during the peak of breeding season. Further investigation is needed to assess the optimal concentration of seminal plasma in the semen diluent and to determine its mechanism of action within the female genital tract.

\section{References}

Ashworth, P. J., Harrison, R. A., Miller, N. G., Plummer, J. M. and Watson, P. F. (1994): Survival of ram spermatozoa at high dilution; protective effect of simple constituents of culture media as compared with seminal plasma. Reprod. Fertil. Developm. 6, 173-180.

Bolet, G. (1986): Timing and extent of embryonic mortality in pigs, sheep and goats: genetic variability. In: Sreenan, J. M. and Diskin, M. G. (eds) Embryonic Mortality in Farm Animals. Martinus Nijhoff, The Hague. pp. 13-43.

Claus, R. (1990): Physiological role of seminal components in the reproductive tract of the female pig. In: Cole, D. J. A., Foxcroft, G. R. and Barbara, J. J. (eds) Control of Pig Reproduction III. Reprod. Fertil. Suppl. 40, 117-131.

Edey, T. N., Kilgour, R. and Bremner, K. (1978): Sexual behaviour and reproductive performance of ewe lambs at and after puberty. J. Agric. Sci. 90, 83-91.

Fahmi, A. H. and Hunter, G. A. (1986): Individual variation in immunosuppressive activity of bovine seminal plasma on Concanavalin A stimulated bovine T-lymphocytes in vitro. J. Dairy Sci. 69, 527-530.

Fahmi, A. H., Hunter, G. A., Markham, F. J. P. and Seguin, E. B. (1985): Identification of an immunosuppressive protein in bovine seminal plasma with activity against bovine lymphocytes. J. Dairy Sci. 68, 2322-2328.

Garner, D. L., Thomas, C. A., Marshall, C. E., DeJarnette, J. M. and Allen, C. H. (1999): Seminal plasma addition protects the viability of diluted bovine sperm. Theriogenology 51, 344 .

Graham, J. K. (1994): Effects of seminal plasma on the motility of epididymal and ejaculated spermatozoa of the ram and bull during the cryopreservation process. Theriogenology 412, 1151-1169.

James, K. and Hargreave, B. T. (1984): Immunosuppression by seminal plasma and its possible clinical significance. Immunol. Today 5, 357-362.

Koch, E. and Ellendorff, F. (1985): Detection of activity similar to that of early pregnancy factor after mating sows with a vasectomised boar. J. Reprod. Fertil. 74, 39-46.

Mann, T. and Lutwak-Mann, C. (1981a): Biochemistry of seminal plasma and male accessory fluids; application to andrological problems. In: Mann, T. and Lutwak-Mann, C. (eds) Male Reproductive Function and Semen. Chapter IX. Springer-Verlag, Berlin-Heidelberg-New York. pp. 269-273. 
Mann, T. and Lutwak-Mann, C. (1981b): Male reproductive function and the composition of semen: General considerations. In: Mann, T. and Lutwak-Mann, C. (eds) Male Reproductive Function and Semen. Chapter I. Springer-Verlag, Berlin-Heidelberg-New York. pp. 28-30.

McRorie, R. A. and Williams, W. L. (1974): Biochemistry of mammalian fertilization. Ann. Rev. Biochem. 43, 777-803.

Ollero, M., Cebrian Perez, J. A. and Muipo Blanco, T. (1997): Improvement of cryopreserved ram sperm heterogeneity and viability by addition of seminal plasma. J. Androl. 18, 732-739.

Töpfer-Petersen, E. (1996): Molecular mechanism of fertilization in the pig. Reprod. Dom. Anim. 31, 93-100.

Waberski, D. (1996): Boar seminal plasma and fertility. Reprod. Dom. Anim. 31, 87-90.

Weitze, K. F., Rabeller, J., Willmen, T. and Waberski, D. (1990a): Interaction between inseminate, uterine and ovarian function in the sow. I. Influence of seminal plasma and oestrogens in the inseminate on intragenital sperm transport, time of ovulation and fertility results in gilts. Reprod. Dom. Anim. 25, 191-196.

Weitze, K. F., Lotz, J. H., Everwand, A., Willmen, T. and Waberski, D. (1990b): Interaction between inseminate, uterine and ovarian function in the sow. II. Investigations into influencing of ovulation by the use of sperm-free media. Reprod. Dom. Anim. 25, 197-204.

Williams, A. H., Lawson, R. A., Cumming, I. A. and Howard, T. J. (1978): Reproductive efficiency of ewe lambs mated at their first and third oestrus of the breeding season. Proc. Austral. Soc. Anim. Prod. 12, 252.

Wilmut, I., Sales, D. I. and Ashworth, C. J. (1986): Maternal and embryonic factors associated with prenatal loss in mammals. J. Reprod. Fertil. 76, 851-864. 